\title{
Histopathological Examination of Newly-Developed Adhesive Silicone Denture Relining Material
}

\author{
M. Tomida ${ }^{1,6}$, K. Nakano ${ }^{2,3,6}$, M. Sato ${ }^{4}$, S. Matsuura ${ }^{5,6}$ and T. Kawakami²,6 \\ ${ }^{1}$ Department of Oral Physiology, Matsumoto Dental University School of Dentistry, Shiojiri, Japan \\ ${ }^{2}$ Hard Tissue Pathology Unit, Matsumoto Dental University Institute for Oral Science, Shiojiri, Japan \\ ${ }^{3}$ Department of Oral Pathology, Matsumoto Dental University School of Dentistry, Shiojiri, Japan \\ ${ }^{4}$ Department of Endodontics and Operative Dentistry, Matsumoto Dental University School of Dentistry, Shiojiri, Japan \\ ${ }^{5}$ Department of Biology, Matsumoto Dental University School of Dentistry, Shiojiri, Japan \\ ${ }^{6}$ Matsumoto Dental University Graduate School of Oral Medicine, Shiojiri, Japan
}

\begin{abstract}
We aimed to evaluate the subcutaneous tissue reaction to a newly developed adhesive silicone denture relining material, SG, Neo Dental Chemical Products Co., Ltd. Tokyo, Japan). We embedded the experimental material SG and another existing control material, Roeko Seal (RS), in the dorsal area of 22 male ddY mice. One week and 12 weeks after the embedding, the tissues surrounding the embedded materials were removed and a histopathological examination was performed. The results demonstrate that the basic histopathological aspects are the formation of granulation tissue and the change of the tissue to fibrous capsule over time. The results suggests that the newlydeveloped SG is safe as compared with the control RS, whose composition is similar.
\end{abstract}

Key words: Tissue reaction; Histopathological evaluation; Silicone-containing material

\section{INTRODUCTION}

Silicone bio-materials are inert, synthetic chemical compounds having a wide variety of forms, as well as various medical and dental uses. Chemically, silicones are polymers that include silicon together with carbon, hydrogen, oxygen, and sometimes other chemical elements. Some common forms include silicone oil, silicone grease, silicone rubber, and silicone resin. Heatresistant and rubber-like silicone materials are commonly used in breast implants, cookware, medical applications, sealants, adhesives, lubricants and insulation.

We have developed a adhesive silicone denture relining material SG and conducted a histopathological evaluation. Because some endodontic materials, such as the root canal filling materials Vitapex [1, 2, 3, 4] and Roeko Seal $[5,6,7,8$, 9] have similar properties, we used chose Roeko Seal for use as a control material.

\section{Materials AND Methods}

\section{EXAMINATION MATERIALS}

The materials examined included the experimental SG Neo Dental Chemical Products, Co, Ltd, Tokyo, Japan) and the control, Roeko Seal (RS, Roeko, Langenau, Germany). The components of the materials are shown in Table 1. The two materials prepared in $6 \mathrm{~mm}$ diameter discoid shapes, in the following thicknesses: $0.76 \mathrm{~mm}$ (SG) or $0.75 \mathrm{~mm}$ (RS). The preparation procedures were performed on a clean bench.

\section{ExAMINATION ANIMALS}

A total of 22 male 9-week-old ddY mice (weighing about $35 \mathrm{~g}$ and purchased from Japan SLC Inc., Hamamatsu, Japan) were bred in plastic cages with Paper clean floor mats (Peparlet Co., Ltd., Shizuoka, Japan) in an air-conditioned room with water and solid diet (Picolab Rodent Diet 20: Japan SLC Inc., Hamamatsu, Japan) during all experimental periods. The Matsumoto Dental University Committee for Animal Experimentation approved the study.

\section{Examination Methods}

Prior to the examination, inhalation anesthesia was used with an isoflurane (Isoflu: Dainippon Sumitomo Pharma Co., Osaka, Japan) and gas-air mixture (4.0\% concentration). Immediately after the dorsal area of the mice was disinfected with $70 \%$ ethanol, an incision was made and the examination materials were injected subcutaneously into the connective tissues. The skin surface at the incision site was sutured using suture string. The site was marked every 2 weeks until the final examination period at 12 weeks (Table 2).

Table 1. Main Components of Experimental and Control Materials.

\begin{tabular}{ll|l}
\hline & Materials & Main Components \\
\hline Experimental & SG & Vinylpolysiloxane, Hydrogenpolysiloxane, Platinum catalyst \\
\hline Control & R S & Polydimethylsiloxane, Silicone oil, Paraffin-base oil, Hexachloroplatinic acid, Zirconium dioxide \\
\hline
\end{tabular}


Table 2. Experimental Periods and Number of Animals.

\begin{tabular}{ll|ll|l}
\hline Periods & & 1 Week & 12 Weeks & Total \\
\hline Experimental & SG & 6 & 5 & 11 \\
\hline Control & RS & 5 & 6 & 11 \\
\hline & \multicolumn{2}{|c|}{ Total } & 22 \\
\hline
\end{tabular}

At 1 week and 12 weeks after injection, 3 mice from each group were anesthetized with isoflurane and gasair mixture, and the tissue surrounding the injection sites were excised. The excised tissues were immediately fixed in 4\% paraformaldehyde/0.5M phosphate buffered solution, embedded in paraffin, and sections were prepared.

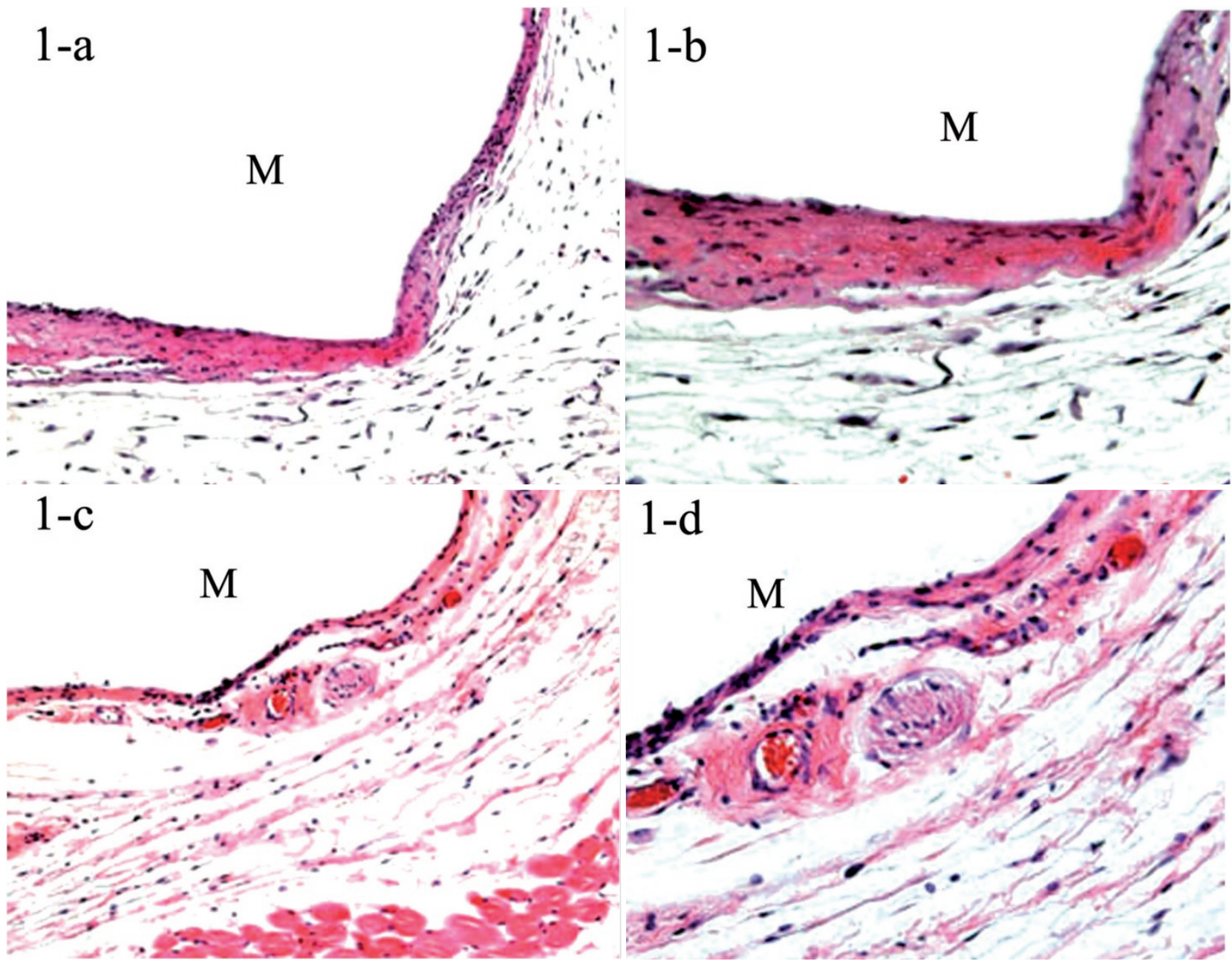

Fig. 1. Experimental (SG) specimen. a: 1-week-specimen, x 50; b: 1-week-specimen, x 100; c: 12-week-specimen, x 50; d: $12-$ week-specimen, x 100.

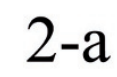

$2-\mathrm{a}$
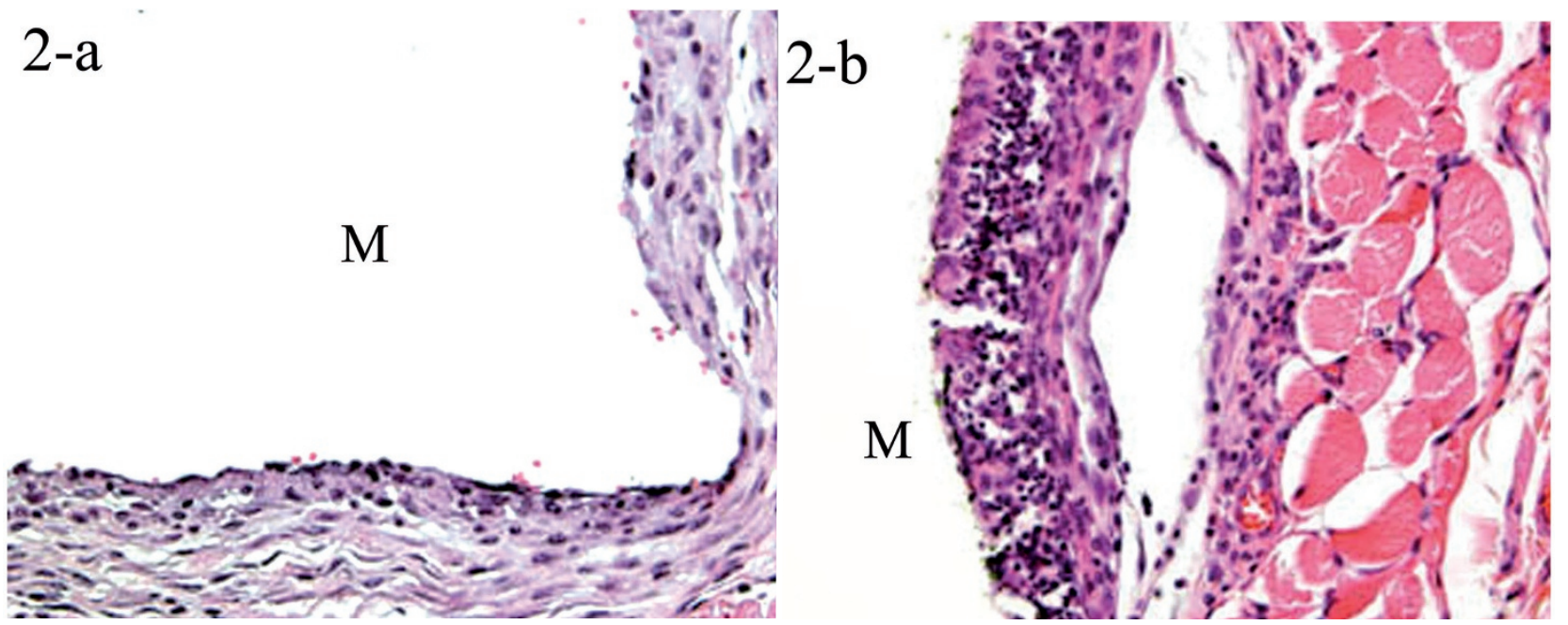

Fig. 2. Control (RS) specimen. a: 1-week-specimen, x 100; b: 12-week-specimen, x 100. 
The tissue sections were stained with hematoxylin and eosin and examined by light microscopy for examination of histopathological changes. We followed the International Organization for Standardization (ISO) guidelines for evaluating the local effects of injection materials $[10,11]$.

\section{RESULTS}

\section{ExPERIMENTAL Group: SG}

The embedded area was composed of quietly-scattered fibrous tissues. In 1-week specimens, there were thin-layered tissues, which consisted of granulation tissues (Fig. 1-a). This granulation tissue consisted some fibroblasts (Fig. 1-b) that had received some damage and thus had degenerated, resulting in necrosis. The surrounding rose, colored connective tissue showed almost no inflammatory cell infiltration and some scattering of red blood cells. In the 12 -week specimens, the encapsulation membrane began reduction of the depth (Fig. 1-c). There was inflammatory cell infiltration, with some enlarged vessels (Fig. 1-d).

\section{CONTROL Group: RS}

Histopathologically, as observed in 1-week specimens, granulation tissue proliferation was evident in the embedded region of RS. The proliferating granulation tissue consisted of numerous palisading collagen bundles, with almost no inflammatory cell infiltration. Slight infiltration was observed at the surface layer of the proliferating granulation tissues, the region in contact with the embedded material RS (Fig. 2-a). After 12 weeks, the thickness of the proliferated granulation tissues was reduced to thin fibrous tissues. However, there was some inflammatory cell infiltration which appeared in the middle-layered portion, especially evident in the determination edge of the material (Fig. 2-b).

\section{Discussion}

There has been considerable literature deveted to examining tissue reactions to biomaterials, especially at the time of development. Our evaluation was made using a comparative histopathological method, with existing materials as controls. We selected the control material RS because the composition and clinical field were nearly the same as for the new-developed SG. We performed our histopathological examinations following the ISO guidelines for evaluating the local effects of injection materials [10, 11].

The results were reported in terms of tissue reactions to the biomaterials. The silicone-containing biomaterials and their biocompatibilities were also investigated. In clinical dentistry, commercially-available silicone-containing materials include Vitapex $[1,2,3,4]$ and Roeko Seal [5, 6, 7, 8, 9]. During present examination, the observation of 1 -week specimens showed that a thin layer of necrotic area was formed. However, under the necrotic tissue, there were also numerous fibroblastic tissues. In RS control specimens, tissue reactions to RS included the formation of granulation tissue and a gradual change into fibrous capsules. There were also some inflammatory cells reactions re- maining in the 12-week specimens. On the other hand, in the experimental SG-group specimens, there were almost no inflammatory cell infiltrations observed in 12 -week specimens. Thus, this histopathological results means the injury irritation of SG is thought to be comparatively weak. Accordingly, we think there are no problems for use inside the human body.

In conclusion, we examined local effects through the subcutaneous tissue reaction to the newly-developed material SG. We used the existing material "Roeko Seal" as a control, and the results demonstrate that the basic histopathological reaction is the formation of fibrous capsule consisting of granulation tissue around the experimental and control embedded materials. Based on the present results, we conclude that the newly-developed SG provides an adequate additional relining material.

\section{REFERENCES}

1. Kawakami T, Nakamura C and Eda S. Fate of ${ }^{14} \mathrm{C}-\mathrm{la}-$ belled dimethylpolysiloxane (silicone oil) in a root canal filling material embedded in rat subcutaneous tissues. Dent Mater 1987; 3: 256-260.

2. Kawakami T and Eda S. Excretion of silicone oil embedded in rat subcutaneous tissue. Med Sci Res 1988; 16: 837.

3. Kawakami T, Nakamura C, Uji H, Hasegawa $\mathrm{H}$ and Eda $\mathrm{S}$. Fate of the silicone oil component of a root canal filling material embedded in rat subcutaneous tissue. J Matsumoto Dent Univ Soc (Matsumoto Shigaku) 1989; 15:167-172.

4. Kawakami T, Yoshikawa M and Eda S. Tissue reactions to dimethylpolysiloxane embedded subcutaneously in rats. Med Sci Res 1990; 18: 485-487.

5. Silva-Herzog D, Ramirez T, Mora J, Pozos AJ, Silva LA, Silva RA and Nelson-Filho P. Preliminary study of inflammatory response to subcutaneous implantation of three root canal sealers. Int Endod J 2011; [doi: 10.111/j.1365-2591.2010.01849.x.]

6. Tanomaru JMG, Cezare L, Goncalves M and Filho MT. Evaluation of the radiopacity of root canal sealers by digitization of radiographic images. J Appl Oral Sci 2004; 12: 355-357.

7. Tanomaru-Filho M, Tanomaru JMG, Leonardo MR and da Silva LAB. Periapical repair after root canal filling with different root canal sealers. Braz Dent J 2009; 20:389-395.

8. Lucena-Martin C, Ferrer-Luque CM, Gonzalez-Rodriquez MP, Robles-Gijon V and de Mondelo JMN-R. A comparative study of apical leakage of Endomethasone, Top Seal, and Roeko Seal sealer cements. J Endod 2002; 28: 423-426.

9. Barbizam JVB, Souza M, Cecchin D and Dabbel J. Effectiveness of a silicon-based root canal sealer for filling of simulated lateral canals. Braz Dent J 2007; 18: 20-23.

10. Upman PJ. ISO 10993-6: Test for local effects after implantation. BONEZone 2006; 5(1): 50-52.

11. International Organization for Standardization (ISO): Biological Evaluation of Medical Devices-Part 1: Evaluation and testing, ISO 10993-1:2003 (E). Geneva, Switzerland. 2003.

Received: April 25, 2011 / Accepted: May 26, 2001

Address for correspondence:

Mihoko Tomida, PhD, Associate Professor,

Department of Oral Physiology,

Matsumoto Dental University School of Dentistry,

1780 Hirooka-Gobara, Shiojiri, 399-0781 Japan

Phone and Fax: +81-263-51-2053

E-mail: $\quad$ motomi@po.mdu.ac.jp 